\title{
Desenh.AR: um recurso educacional desenvolvido de forma interdisciplinar com base em aprendizagem baseada por projetos
}

\section{Mauricio Capobianco Lopes ${ }^{1}$, Dalton Solano dos Reis ${ }^{2}$, Gabriel Brogni Bento ${ }^{2}$, Arline Thomé da Silva ${ }^{3}$, Clara Isabela Ferreira Bauer ${ }^{3}$, Nicolas José Cordeiro Viana ${ }^{2}$, Pietra Larissa Zoschke $^{3}$}

\author{
${ }^{1}$ Programa de Pós-Graduação em Ensino de Ciências Naturais e Matemática \\ Universidade Regional de Blumenau (FURB) - Rua Antonio da Veiga, 140 - CEP 89.030-903 - \\ Blumenau, SC - Brasil \\ ${ }^{2}$ Departamento de Sistemas e Computação \\ Universidade Regional de Blumenau (FURB) - Blumenau, SC - Brasil \\ ${ }^{3}$ Departamento de Educação \\ Universidade Regional de Blumenau (FURB) - Blumenau, SC - Brasil \\ mclopes@furb.br, dalton@furb.br, gbbento@fub.br, arlines@furb.br, \\ cifbauer@furb.br, njcvianalfurb.br, pzoschke@furb.br
}

\begin{abstract}
This paper presents an interdisciplinary experience of developing an educational resource based on the Project-Based Learning method involving the Computer Science and Pedagogy courses at the Regional University of Blumenau. In the active method used, students from both courses jointly developed an educational resource based on digital technologies. As result, an educational resource named Desenh.AR was developed by using Leap Motion technology. These resource aims to develop motor and space skills, to stimulate creativity and autonomy, and to create and illustrate stories for 4 th grade students in elementary education. We concluded that there are challenges and difficulties in developing a project in an interdisciplinary manner, but there are significant gains for students' learning and experience.
\end{abstract}

Resumo: $O$ presente artigo apresenta uma experiência interdisciplinar de desenvolvimento de um recurso educacional com base no método da Aprendizagem Baseada em Projetos envolvendo os cursos de Ciência da Computação e Pedagogia da Universidade Regional de Blumenau. No método ativo utilizado, os estudantes de ambos os cursos desenvolveram juntos um recurso educacional tendo como base as tecnologias digitais. Como resultado, foi desenvolvido o Desenh.AR, um recurso educacional utilizando o Leap Motion voltado para o desenvolvimento motor e espacial, estímulo à criatividade e à autonomia e criação e ilustração de histórias para estudantes do $4^{\circ}$ ano da educação fundamental. Conclui-se que há grandes desafios e dificuldades em se desenvolver um projeto de forma interdisciplinar, mas há ganhos significativos para a aprendizagem e experiência dos estudantes.

\section{Introdução}

As mudanças sócio culturais pelas quais a humanidade tem passado, sobretudo ligada a evolução das tecnologias digitais tem impactado diretamente nos processos educacionais. Moran (2013) ressalta que neste contexto "A escola precisa reaprender a ser uma organização efetivamente significativa, inovadora, empreendedora" [Moran, 2013, p. 12]. Uma das possibilidades de transformar os espaços de ensino e aprendizagem é com base no uso de métodos ativos os quais 
VIII Congresso Brasileiro de Informática na Educação (CBIE 2019)

Anais dos Workshops do VIII Congresso Brasileiro de Informática na Educação (WCBIE 2019)

pressupõem um modelo educacional no qual "[...] o aluno se torna protagonista e assume mais responsabilidades sobre seu processo de aprendizagem [...] [Mattar, 2017, p. 21].

Os métodos ativos são estratégias pedagógicas amplas, genéricas e sistematizadas que se sustentam por um conjunto diverso de métodos e técnicas para o alcance dos objetivos pedagógicos, combinados para atender diferentes perfis de estudantes e se apoiarem fortemente nas tecnologias digitais [Masetto 2015; Mattar 2017; Moran, 2018]. Um dos métodos ativos bastante utilizados é a Aprendizagem Baseada em Projetos.

A Aprendizagem Baseada em Projetos (ABP) trata de apresentar um desafio que não seja trivial e que promova o engajamento dos estudantes (Buck Institute for Education, 2008). Entre os princípios destacados por Mattar (2017) para caracterizar um método como ABP destacam-se: o foco em objetivos de aprendizagem dos alunos, um problema significativo e desafiador, a investigação permanente sobre o objeto, o impacto no mundo real, as escolhas dos estudantes, a reflexão sobre o processo, o feedback constante e a publicização da produção para além da sala de aula. Assim, os estudantes devem encarar o desafio de solucionar um problema do mundo real e dar visibilidade a eles [Bender, 2014].

Com base nisso, em 2014 iniciou-se na Universidade Regional de Blumenau, nas disciplinas de Sistemas Multimídia do curso de Ciência da Computação e Educação e Tecnologias Digitais do curso de Pedagogia, uma experiência de desenvolvimento de recursos educacionais, envolvendo os estudantes de ambos os cursos. Em média, têm sido desenvolvidos sete produtos por semestre. Além dos cursos de Computação e Pedagogia, a iniciativa envolveu, em alguns semestres, estudantes de Matemática e Química.

Assim, o presente artigo tem por objetivo apresentar uma experiência interdisciplinar de desenvolvimento de um recurso educacional com base no método da Aprendizagem Baseada em Projetos envolvendo os cursos de Ciência da Computação e Pedagogia da Universidade Regional de Blumenau realizada no primeiro semestre do ano de 2019. No método ativo utilizado, os estudantes de ambos os cursos desenvolveram juntos um recurso educacional tendo como base as tecnologias digitais. Como resultado, foi desenvolvido o Desenh.AR, um recurso educacional utilizando o Leap Motion voltado para o desenvolvimento motor e espacial, estímulo à criatividade e à autonomia e criação e ilustração de histórias para estudantes do $4^{\circ}$ ano da educação fundamental.

Destaca-se que ao se pesquisar pelo termo "Aprendizagem Baseada em Projetos" nos anais do SBIE foi encontrado apenas o trabalho de Santoro, Borges e Santos (2002) com foco diferente do apresentado no presente artigo. Já a busca pelo termo "metodologias ativas" retornou dois trabalhos [Santo; Sabio; Souza, 2016; Souza; Vergottini; Benini, 2018] também com foco diferente da abordagem do presente texto.

\section{Método}

Para o desenvolvimento do recurso educacional, foi utilizada o método ativo da Aprendizagem Baseada em Projetos. Os estudantes do curso são reunidos no Laboratório Interdisciplinar de Formação de Educadores (LIFE) da Universidade e tem encontros semanais equivalente à metade da carga horária de cada uma de suas disciplinas. Assim, o delineamento do projeto foi realizado conforme apresentado a seguir.

No primeiro encontro (conhecendo a organização do projeto) os estudantes tomam conhecimento do método da disciplina e tem uma rápida explicação sobre o que acontece ao longo do semestre e também sobre as possibilidades tecnológicas disponíveis. Os grupos da Computação e da Pedagogia escolhem sua tecnologia separadamente, sem conhecerem uns aos outros. Neste caso específico do projeto aqui apresentado, o recurso escolhido foi o Leap Motion; 
VIII Congresso Brasileiro de Informática na Educação (CBIE 2019)

Anais dos Workshops do VIII Congresso Brasileiro de Informática na Educação (WCBIE 2019)

No segundo encontro (definição do projeto) os estudantes dos dois cursos são agrupados segundo a tecnologia escolhida, sendo constituídos os grupos que irão trabalhar ao longo do semestre. Além de se conhecer, é necessário definir o projeto sobre o qual irão trabalhar. As estudantes de Pedagogia devem partir de um problema ou prática que observam em seus estágios ou em sua atuação profissional e que podem ser melhor trabalhados a partir das tecnologias. Os estudantes de Computação ajudam a refletir como desenvolver o recurso a partir das necessidades apontadas. Esta etapa conta com a mediação direta dos professores de modo que não se constitua um projeto muito simples ou que não seja factível. No presente projeto, uma das estudantes da Pedagogia já trabalhava com a criação de histórias utilizando recursos analógicos com seus estudantes. Assim, foi definida que uma dinâmica semelhante seria usada no projeto. É importante destacar que os professores sempre incitam os estudantes a pensar sobre qual o ganho efetivo que a tecnologia pode proporcionar para a aprendizagem dos alunos da Educação Básica, que difere o uso do recurso digital com o analógico. Neste caso específico, justificou-se pela diferença no desenvolvimento motor proporcionado pelo uso do Leap Motion.

No terceiro e quarto encontros (formalização do projeto) os estudantes devem formalizar sua proposta. É solicitado que definam: situação-problema, objetivo do projeto, objetivos de aprendizagem (para os estudantes da Educação Básica), público-alvo, área e sub-área do conhecimento e a tecnologia. O objetivo foi utilizar o Leap Motion como recurso de aprendizagem e de desenvolvimento motor e espacial, estimulando a criatividade e a autonomia dos estudantes do $4^{\text {o }}$ ano na criação e ilustração da história. Os objetivos de aprendizagem eram: estimular a criatividade por meio da produção artística com base nos recursos tecnológicos digitais; explorar e reconhecer elementos constitutivos das artes visuais (ponto, linha, forma, cor, espaço); desenvolver a habilidade motora fina.

Os estudantes desenvolverem um flyer na ferramenta Canva (www.canva.com) (Figura 1) com a descrição do projeto, a qual constitui-se como a etapa 1 do desenvolvimento. O flyer foi avaliado por integrantes de dois outros grupos da turma.

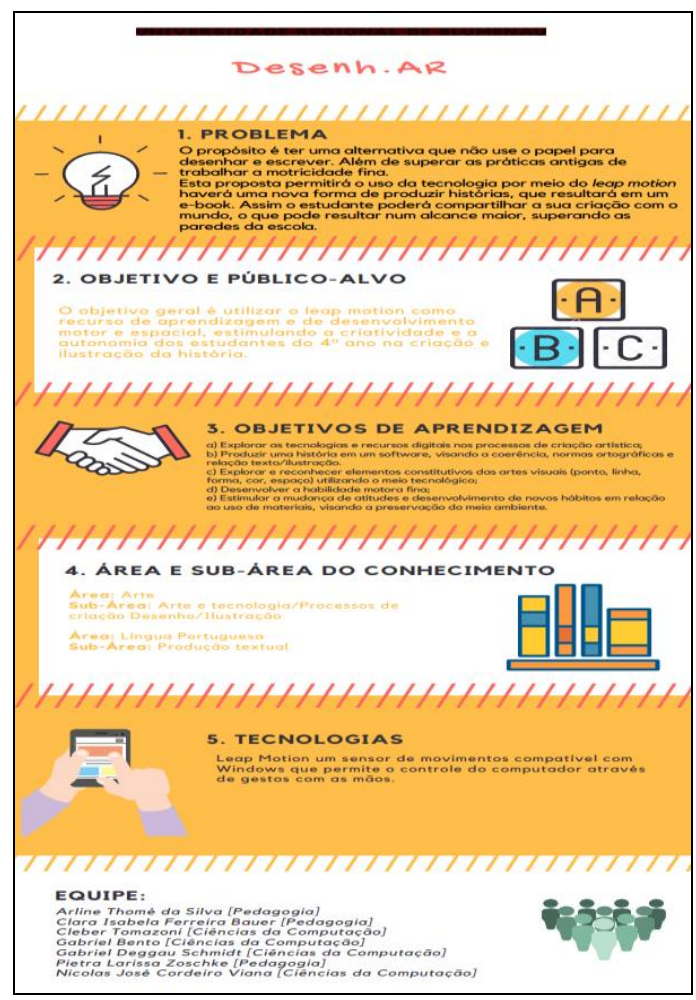

Figura 1 - Etapa 1 do projeto 
VIII Congresso Brasileiro de Informática na Educação (CBIE 2019)

Anais dos Workshops do VIII Congresso Brasileiro de Informática na Educação (WCBIE 2019)

No quinto encontro os estudantes devem definir em conjunto os requisitos funcionais do software, bem como os prazos de entrega de cada um deles. Para esse acompanhamento os estudantes utilizam a ferramenta Trello (www.trello.com). Também devem produzir um desenho esperado das telas do sistema.

Do sexto ao décimo segundo encontros (execução do projeto) os estudantes trabalham no desenvolvimento do projeto, com atividades específicas. As estudantes de Pedagogia produzem um documento no qual deve constar os seguintes itens:

a) introdução: devem descrever o contexto, o problema, as justificativas e a motivação para o desenvolvimento do produto educacional;

b) objetivo geral: devem descrever o objetivo geral do produto educacional;

c) objetivos de aprendizagem: devem detalhar os objetivos de aprendizagem do produto educacional;

d) público-alvo: devem descrever o público-alvo do produto educacional;

e) fundamentação teórica: a partir dos construtos definidos nos objetivos, devem inserir uma breve fundamentação com os principais conceitos e autores que embasam o trabalho. Devem consultar os documentos oficiais, tais como BNCC, PCNs e DCMs e apresentar a concepção pedagógica do projeto. Também devem incluir uma seção que trate do uso das tecnologias digitais na educação;

f) trabalhos correlatos: devem descrever dois correlatos com objetivos de aprendizagem similares ao produto proposto: um com o uso de tecnologia digital e outro sem o uso de tecnologia digital;

g) roteiro pedagógico (sequência didática): devem descrever o roteiro pedagógico (sequência didática) de aplicação do produto educacional, ou seja, como será utilizado em sala de aula.

Enquanto os estudantes de Pedagogia produzem este documento, os de Computação trabalham no desenvolvimento computacional do projeto. Ao final do décimo segundo encontro a implementação computacional deve estar em condições de ser utilizada pelo menos em formato de protótipo. Em todos os encontros, os estudantes devem conversar para ver se as produções estão convergentes, assim como os professores acompanham o desenvolvimento do projeto e mediam eventuais conflitos, problemas ou dúvidas. A finalização deste último encontro constitui o fim da Etapa 2 do Projeto.

No décimo terceiro encontro os estudantes recebem um feedback sobre suas produções. Os estudantes de Pedagogia recebem uma versão anotada do documento produzido e os de Computação se os requisitos estão devidamente atendidos. As estudantes de Pedagogia são motivadas a aplicar o roteiro pedagógico definido junto ao público-alvo. No presente projeto, em função do atraso e das dificuldades enfrentadas pela turma de Computação, tal aplicação não foi realizada. A partir desse encontro, até o décimo sexto encontro, as estudantes de Pedagogia devem complementar o documento em texto, inserindo as seguintes descrições:

a) descrição do software: devem descrever detalhadamente o software, apresentando as telas e explicando as suas principais funções. Esta descrição será apresentada a seguir;

b) aplicação da sequência didática (opcional); devem descrever a aplicação da sequência didática com o público-alvo. Conforme destacado, anteriormente, não foi realizada neste projeto; 
VIII Congresso Brasileiro de Informática na Educação (CBIE 2019)

Anais dos Workshops do VIII Congresso Brasileiro de Informática na Educação (WCBIE 2019)

c) resultados e discussões: devem descrever os principais resultados alcançados com a proposta e discutir as principais dificuldades e limitações, além de comparar seu trabalho com os correlatos. Esta descrição será apresentada a seguir.

d) conclusões e sugestões: devem apresentas conclusões sobre o projeto indicando se os objetivos foram alcançados - ou não.

No décimo sétimo e décimo oitavo encontros os estudantes socializam com seus colegas os projetos produzidos. A socialização é feita na forma de estações. Assim, os estudantes dos demais grupos interagem e realizam as atividades de todos os demais grupos. A Figura 2 (a) apresenta um exemplo das atividades na sala e a Figura 2 (b) especificamente para o uso do Desenh.AR.

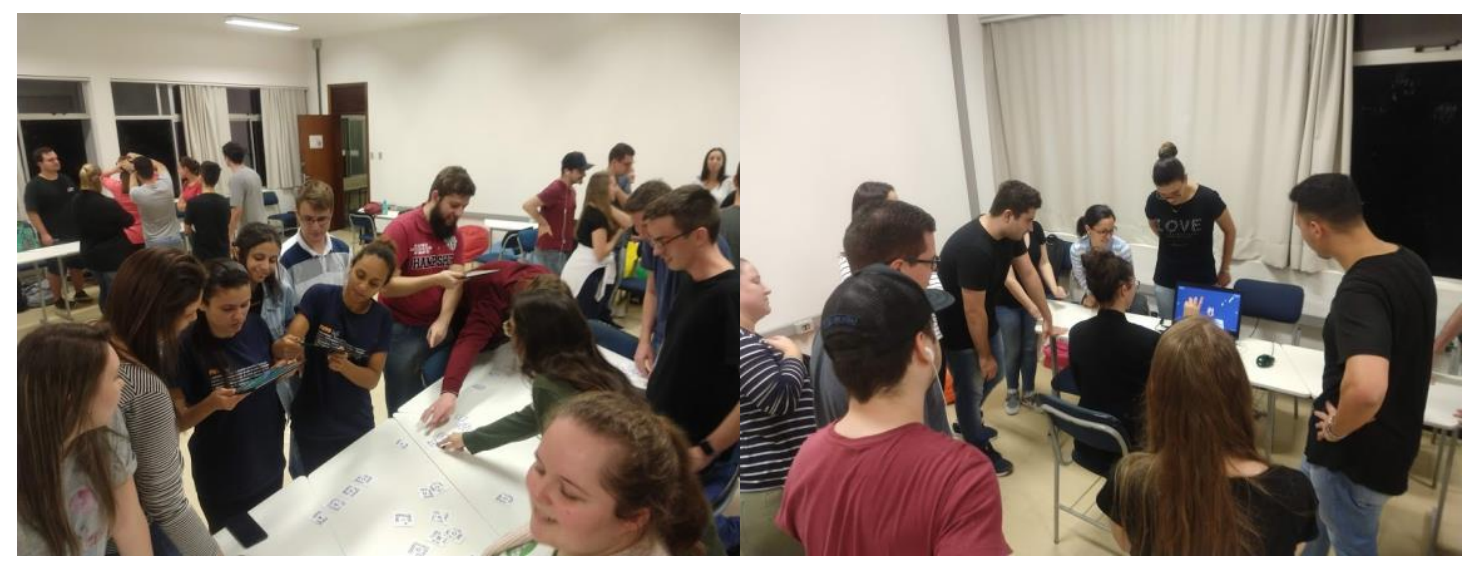

(a)

(b)

Figura 2 - Socialização dos projetos

Esta atividade fecha a Etapa 3 do Projeto. O documento final produzido pode ser solicitado aos autores do artigo para conhecimento. Cabe destacar que no dia da apresentação do projeto, havia na sala uma criança, filho de um aluno do curso de Computação, o qual foi entrevistado sobre o recurso educacional. Suas impressões são apresentadas no capítulo seguinte.

\section{Resultados}

Como resultados do projeto destaca-se, além do documento citado, a proposta de roteiro pedagógico e o software, bem como a entrevista com a criança que utilizou o recurso.

O roteiro pedagógico produzido é apresentado na Tabela 1. Nota-se que a ideia final do produto é que a criança produza um e-book com seus desenhos e a história criada por ela.

Tabela 1 - Roteiro Pedagógico

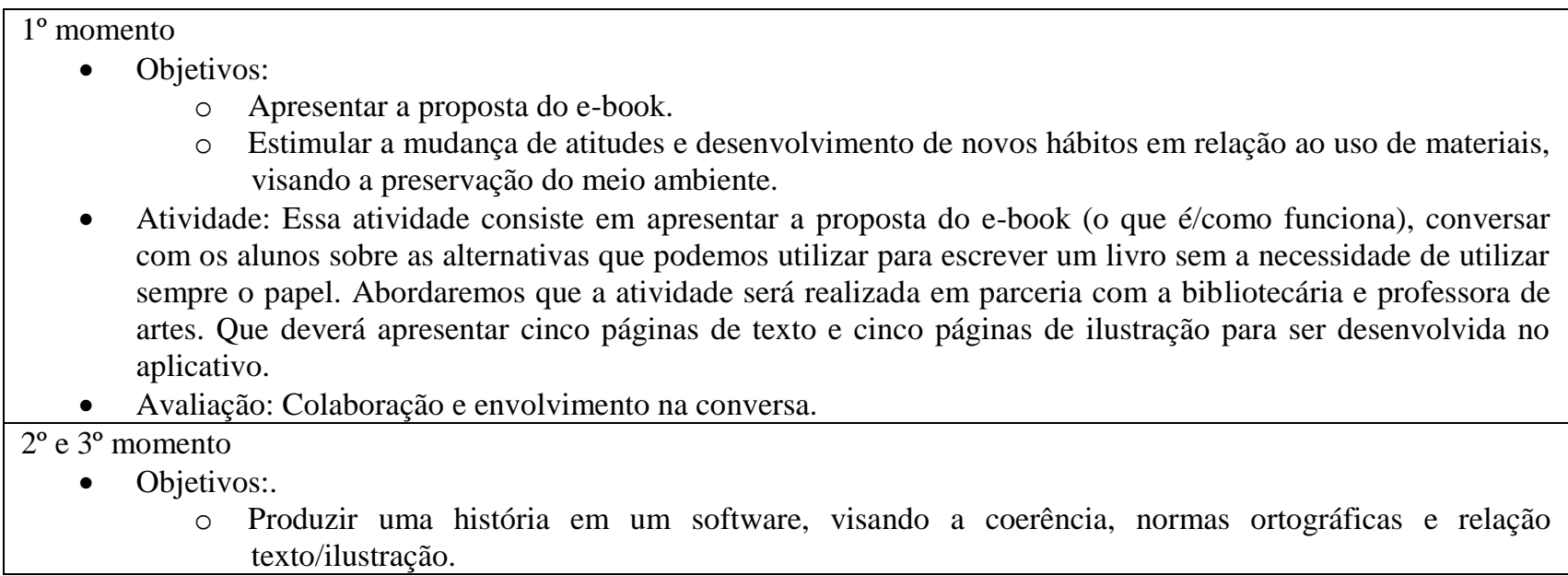


VIII Congresso Brasileiro de Informática na Educação (CBIE 2019)

Anais dos Workshops do VIII Congresso Brasileiro de Informática na Educação (WCBIE 2019)

- Atividade: Os alunos na sala de informática produzirão a história utilizando a ferramenta de texto word. Nesse momento a professora estará auxiliando os alunos nas questões de ortografia, coesão, coerência, nas dúvidas e necessidades.

- Avaliação: Produção da história dentro dos critérios de ortografia, coerência, coesão e etc.

$4^{\circ}$ momento

- Objetivos:

○ Produzir esboço das ilustrações;

- Explorar e reconhecer elementos constitutivos das artes visuais (ponto, linha, forma, cor e espaço) utilizando o meio tecnológico.

- Atividade: Durante a aula de artes a professora regente realizará a revisão da história de forma individual e a professora de artes auxiliará os alunos na iniciação do esboço das ilustrações que será realizada em tablets.

- Avaliação: Na revisão da história produzida o aluno será avaliado se escreveu conforme os critérios definidos. Na elaboração do esboço da ilustração se está fazendo relação com o texto e ilustração.

$5^{\circ}$ e demais momentos necessários

- Objetivos:

○ Explorar as tecnologias e recursos digitais nos processos de criação artística;

- Desenvolver a habilidade motora fina.

- Atividade: Elaboração da construção do e-book no aplicativo. Essa atividade ocorrerá de forma individual (considerando que haverá apenas um recurso tecnológico) nas aulas de leitura da biblioteca e nas aulas de artes. Os demais alunos estarão realizando as atividades propostas da aula.

- Avaliação: Participação e empenho na realização da atividade.

Último momento:

- Objetivo:.

○ Socializar a história produzida.

- Atividade: Nesse momento os alunos compartilharão as histórias produzidas com seus colegas e demais turmas no auditório da escola. Divulgação dos e-books no blog da escola.

- Avaliação: Participação dos alunos na exibição de seus trabalhos e colaboração na apresentação do trabalho do colega.

O software produzido é destacado a seguir. A Figura 3 apresenta a tela inicial do Desen.AR a partir da qual é possível criar uma nova história, ler as histórias criadas por outros alunos ou realizar um desenho livre.

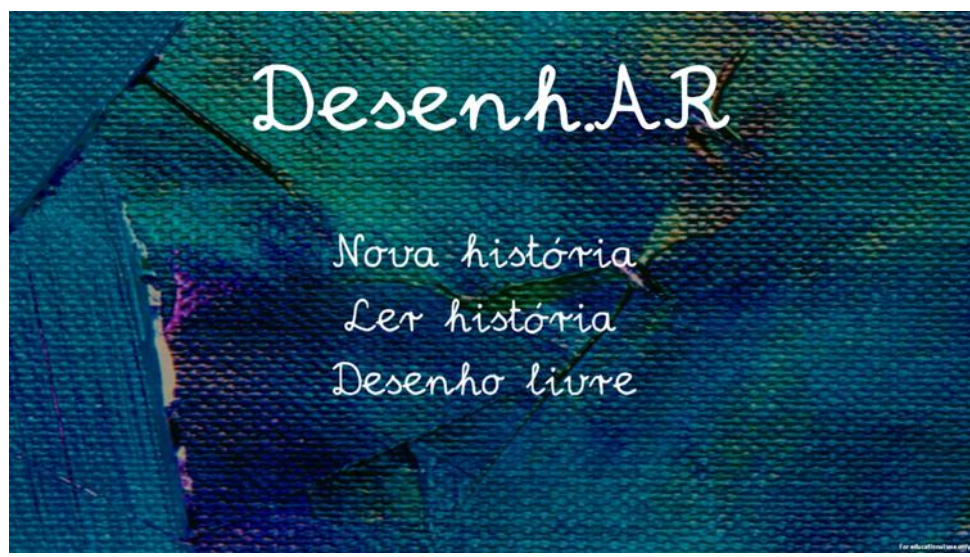

Figura 3 - Tela inicial do Desenh.AR

Ao clicar em "Nova história" o estudante é levado para uma tela com uma caixa de texto (Figura 4). A edição/criação da história consiste no desenvolvimento de cinco páginas de texto e cinco desenhos. É possível avançar para a próxima página por meio do botão azul localizado à direita e voltar à página anterior com o botão do lado oposto. 


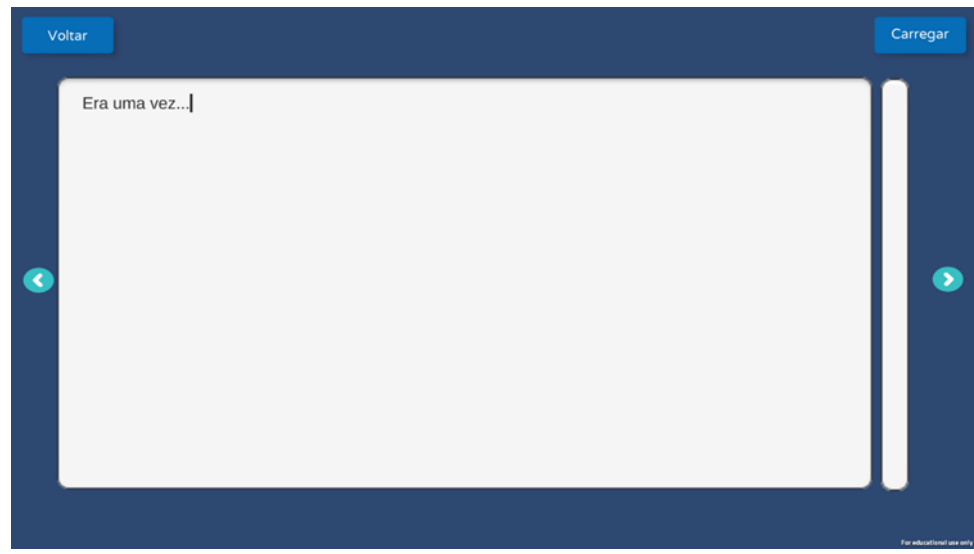

Figura 4 - Tela para escrita da história

Para o desenho é utilizado o LeapMotion (sensor que capta o movimento das mãos). Juntando o polegar e o indicador da mão direita, o sistema reconhece que o usuário está iniciando o desenho. Enquanto esses dois dedos são movimentados juntos pela tela, eles são seguidos por uma linha, tornado possível realizar desenhos no ar. Para parar o desenho (pausar a linha), basta afastar os dois dedos.

Para trocar a cor da linha, é preciso juntar e soltar (como um clique) o indicador e o polegar da mão esquerda. Assim, são apresentadas três caixas com as cores vermelho, verde e azul. A seleção das cores é feita através da mão direita, bastando "tocar" com a palma da mão na cor desejada. A cor selecionada fica em um tom mais claro, indicando que está ativa. Para desmarcar a cor é preciso tocar novamente nela. Além das cores básicas exibidas, é possível misturá-las, deixando mais de uma cor selecionada. Por exemplo: com o vermelho e o verde selecionados, a linha fica amarela. A cor do que já está desenhado não é afetada, ela apenas vale para os próximos traços, possibilitando a utilização de várias cores em um mesmo desenho. Para fechar o menu de cores, é necessário encostar o polegar e o indicador da mão esquerda da mesma forma que deve ser realizado para que se abra.

Também é possível desfazer o último traço, clicando no botão "apagar", pois não há borracha. Não existe um limite de traços que pode ser feito em cada desenho. A Figura 5 apresenta a tela para o desenho da história com a representação da mão feita pelo Leap Motion.

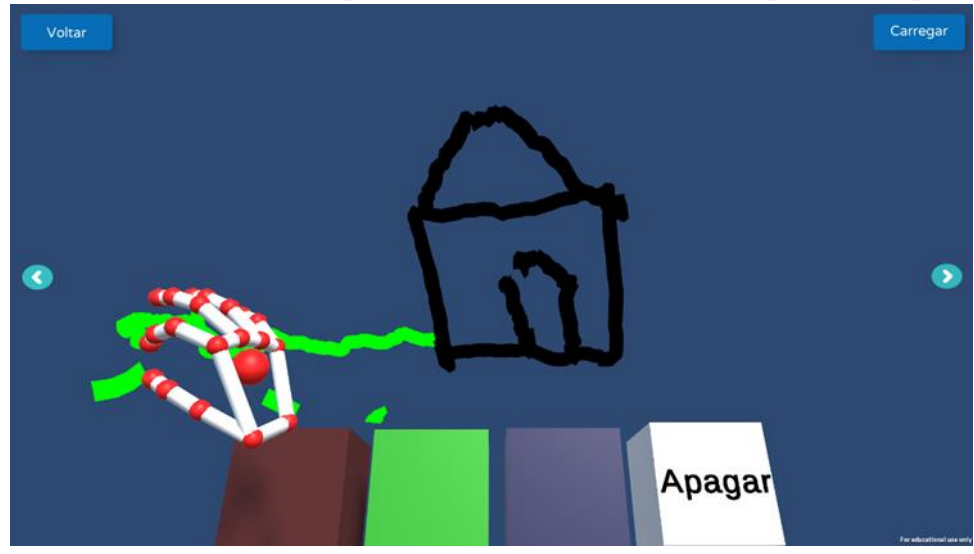

Figura 5 - Tela para desenho da história

A tela de leitura carrega a última história salva (Figura 6). A navegação entre as páginas da história é feita da mesma forma que na tela de nova história, utilizando os botões de avançar e voltar. Nessa tela não é possível editar o texto, nem os desenhos, somente visualizar. 


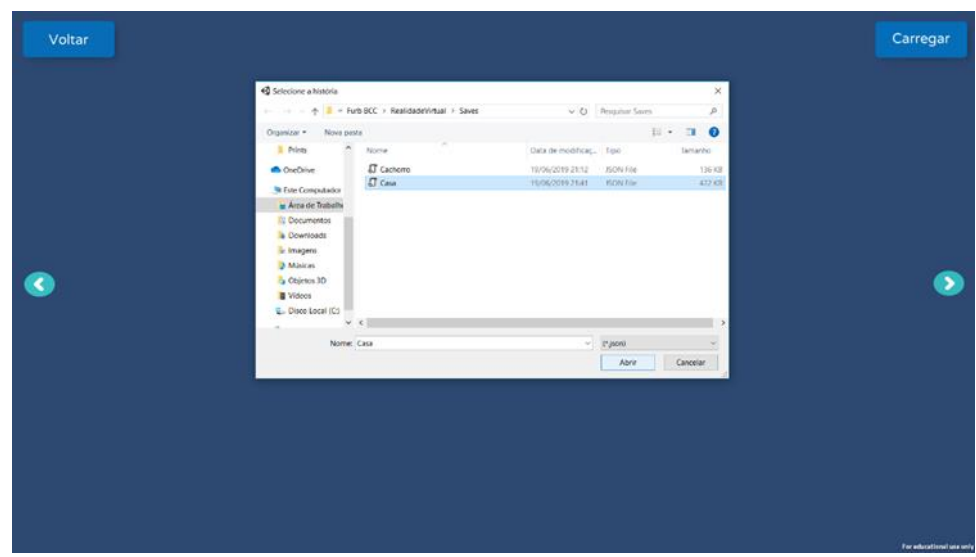

Figura 6 - Tela para leitura da história

Por fim, na Figura 7 é apresentada a opção de desenho livre. Ela funciona da mesma forma que os desenhos realizados na tela de nova história, porém é não está associado a nenhuma história ou texto e pode ser utilizado como recurso de treinamento.

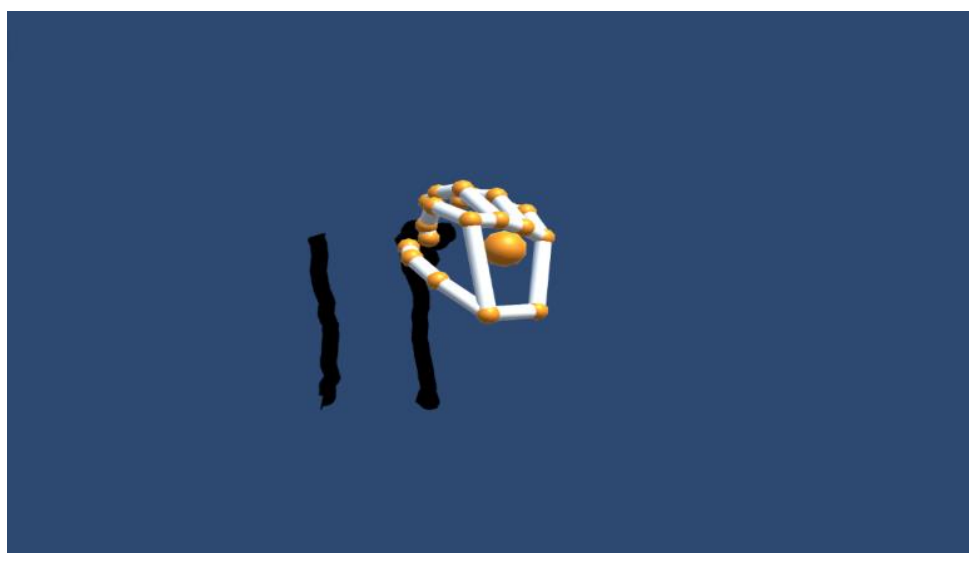

Figura 7 - Tela para desenho livre

Conforme destacado anteriormente, no momento da aplicação com os estudantes da turma, havia presente na sala uma criança de 10 anos, filho de um dos estudantes do curso de Ciência da Computação. Assim, além de experimentar o software com os demais estudantes da turma, o mesmo também foi testado com a criança.

Inicialmente conversou-se com a criança a respeito do projeto a qual foi convidada a usar o software. Após a aceitação da criança, explicou-se como ela deveria utilizar o recurso. Houve uma conversa com ela sobre que história ela gostaria de escrever, a qual disse que gostava de histórias de lutas e a partir disso, iniciou sua história, que envolvia personagens do desenho Bob Esponja. Percebemos algumas dificuldades na escrita correta do texto, questões de coerência e pontuações, entretanto pelo tempo limitado que tínhamos para aplicar com essa criança, não abordamos isso com ela. Na produção do desenho ela compreendeu como deveria movimentar as mãos e produziu um desenho livre para experimentar o recurso. Ao final, conversamos com ela sobre o que achou do projeto e ela respondeu que gostou bastante, mas que achou um pouco difícil, porém disse que se talvez treinasse mais poderia ser melhor. Também comentou que prefere escrever do que desenhar. Perguntamos se seria interessante se houvesse um recurso desse na escola e ela afirmou que sim. Comentamos que esse recurso possibilitaria que ela enviasse a história dela para outras pessoas por meio eletrônico, já que o produto final seria um e-book. Ela gostou da ideia e disse que enviaria para o tio que mora longe. 
VIII Congresso Brasileiro de Informática na Educação (CBIE 2019)

Anais dos Workshops do VIII Congresso Brasileiro de Informática na Educação (WCBIE 2019)

Já com a aplicação para a turma de Pedagogia e Ciência da Computação foram percebidas propostas diferentes para utilizar o Leap Motion e o produto educacional, além de algumas dificuldades e limitações quanto ao seu uso. Ao ser realizada a apresentação deste produto educacional, algumas propostas diferentes foram dadas à aplicação: os acadêmicos de Pedagogia realizaram a criação de uma história coletiva, no qual cada sujeito criava uma página de texto e outra de ilustração dando continuidade à história. Nesta proposta houve grande interação e participação do grupo.

Apesar do uso do Leap Motion ser considerado simples, foi perceptível a dificuldade encontrada pelos acadêmicos e pela criança para utilizar o recurso educacional produzido. Diante desse cenário, vê-se necessário haver treino antes de ser colocado em prática a sequência didática da proposta. Desta forma, pode-se utilizar o recurso "desenho livre" no produto a fim de praticar até o indivíduo entender como o mesmo funciona.

Ao perguntar para a criança e os demais que testaram o produto educacional, todos relataram que é uma ideia interessante para montar história, pois não estão restritos ao papel e caneta, e a experiência é diferente. Foram feedbacks importantes, pois a proposta inicial do projeto era sair do modo convencional e fazer com que o ato de produzir a história de fosse atrativo.

Especificamente em relação ao projeto desenvolvido ao longo do semestre, a equipe encontrou dificuldades, tanto para se entender no seu início, uma vez que as linguagens e visões de mundo das áreas eram diferentes, bem como com a tecnologia. $\mathrm{O}$ desenvolvimento para o Leap Motion demandou mais tempo que o esperado e as respostas não eram totalmente confiáveis. Em alguns momentos o recurso tecnológico funcionava corretamente e, em outros, seguindo o mesmo procedimento, ele já não funcionava. Este comportamento incerto gerou frustração e algumas discussões entre os integrantes do grupo em vários momentos ao longo do semestre. De qualquer modo, a experiência foi válida pois foi possível compreender as dificuldades e características das duas áreas envolvidas no projeto.

\section{Conclusões e Sugestões}

Ao analisar o desempenho do produto educacional Desenh.AR durante as apresentações, foi possível perceber a necessidade de praticar o uso do recurso tecnológico antes da realização da sequência didática para que seja possível alcançar os objetivos propostos efetivamente. $\mathrm{O}$ aplicativo desenvolvido ao longo do projeto poderia ter mais opções de cores, traços e fundos, proporcionando desenhos ainda mais criativos. Porém, isto dificultaria ainda mais o processo de criação, pois teriam mais elementos a serem praticados antes de serem efetivamente utilizados durante a aplicação da sequência didática. Utilizando o software, um notebook e um Leap Motion é possível construir uma história e disponibilizá-la online, atingindo o público alvo desejado. Concluímos que o produto cumpre boa parte do que foi planejado, entretanto para utilizá-lo numa sequência didática, precisamos ajustá-lo para que melhor desempenho.

Em relação à experiência do trabalho realizado segunda o método da Aprendizagem Baseada em Projetos de modo interdisciplinar, algumas considerações são importantes: a primeira é a dificuldade em se estabelecer o que será desenvolvido. Nesta etapa, a principal dificuldade inicial para as estudantes de Pedagogia foi compreender as potencialidades da tecnologia selecionada e o que poderia ser feito com ela. Para os alunos da Computação, habituados a desenvolver softwares a partir de sua própria ideia, também houve dificuldade em compreender o sentido do que seria feito. Daí decorre a segunda dificuldade: estabelecer o diálogo entre as áreas. Na formação tradicional os estudantes ficam fechados em seus conhecimentos, com pouca ou nenhuma interação para a solução de problemas em conjunto com outras. $\mathrm{O}$ projeto evidenciou os problemas em dialogar e compreender as particularidades e necessidades de cada área do conhecimento. Outra dificuldade residiu no cumprimento dos prazos e das tarefas. Uma vez que o Leap Motion é um recurso 
computacional pouco conhecido e utilizado, o projeto gerou alguns atrasos e não cumpriu exatamente o que se esperava inicialmente o que também gerou, em certos momentos, frustrações e desentendimentos entre os membros da equipe.

Por outro lado, as dificuldades apontadas converteram-se em aprendizagens, entre as quais destacam-se: a convivência permanente com outra área de conhecimento o que é natural em qualquer campo de trabalho; a pressão por prazos e entregas ; a avaliação e feedback permanente dos professores ao longo do processo, ao invés de ser feita pontualmente em provas ou em trabalhos extraclasse; a solução de conflitos para que o projeto tivesse o andamento adequado; e a realização de um produto completo e avaliado por uma criança e pelos pares de duas áreas de conhecimento.

A partir da experiência, conclui-se que o método proposto foi efetivo e proporcionou aprendizagem uma vez que os estudantes tinham tarefas e ações permanentes ao longo do processo, sem perder de vista os conceitos e conteúdos específicos de cada área do conhecimento, os quais foram essências e necessários para o desenvolvimento do recurso educacional proposto.

\section{Agradecimentos}

Agradecemos à Fundação de Apoio à Pesquisa e Inovação do Estado de Santa Catarina (FAPESC) pelo financiamento ao (LIFE) da (FURB) e à FURB pelas condições oferecidas para a realização deste trabalho.

\section{Referências}

Bender, W. N. (2014). “Aprendizagem baseada em projetos: educação diferenciada para o século XXI". Porto Alegre: Penso.

Buck Institute for Education. (2008). “Aprendizagem baseada em projetos: guia para professores do ensino fundamental e médio". Porto Alegre: Artmed.

Masetto, Marcos T. (2015). "Desafios para a Docência Universitária na Contemporaneidade: professor e aluno em inter-ação adulta". São Paulo: Avercamp.

Mattar, João. (2017) "Metodologias ativas: para a educação presencial, blended e a distância". São Paulo: Artesanato Educacional.

Moran, José. (2018) "Metodologias ativas para uma aprendizagem mais profunda". In: Bacich, Lilian; Moran, José. Metodologias ativas para uma educação inovadora: uma abordagem teóricoprática. Porto Alegre: Penso.

Moran, J. M. (2013) "Ensino e aprendizagem inovadores com o apoio das tecnologias". In: Moran, J. M.; Masetto, M. T.; Behrens, M. A. Novas tecnologias e mediação pedagógica. 21. ed. Campinas, SP: Papirus.

Santoro, F., Borges, M., \& Santos, N. (2002). "Um Modelo de Cooperação para Aprendizagem Baseada em Projetos com Foco no Processo Cooperativo e Workflow". Brazilian Symposium on Computers in Education (Simpósio Brasileiro de Informática na Educação - SBIE), 1(1), 358367.

Santos, H., Sabio, G., \& Souza, W. (2016). Abordagem em Realidade Aumentada para Momentos de Aprendizagem Autodirigida. Brazilian Symposium on Computers in Education (Simpósio Brasileiro de Informática na Educação - SBIE), 27(1), 42.

Souza, D., Vergottini, V., \& Bernini, D. S. D. (2018). "Educação dos tempos modernos através da aprendizagem colaborativa: uma abordagem sobre EDUSCRUM". Brazilian Symposium on Computers in Education (Simpósio Brasileiro de Informática na Educação - SBIE), [S.1.], p. 51. 